\title{
Ultra-thin films on complex metallic alloy surfaces: A perspective
}

Vincent Fournée, Julian Ledieu, Émilie Gaudry, Hem-Raj Sharma, Ronan McGrath

\begin{abstract}
Complex metallic alloys (CMAs) may be defined as those intermetallic compounds having large $(>\approx n m)$ unit cell dimensions. This includes quasicrystals as a special case, the unit cell being infinite. The discovery of quasicrystals motivated the study of CMAs, and the surface science community became active in the field once stable samples of sufficient size were produced. While the initial surface science activity centred on clean surface preparation, increasingly the formation of thin films, both metallic and molecular grew in importance. In this chapter we give a brief introduction to this topic, and then focus on several current areas of interest. These include the growth and characterisation of ultrathin metallic films of diverse architectures, the formation through deposition of novel molecular overlayers and thin films, complex intermetallics as surface alloys, and the potential use of intermetallic surfaces for catalytic reactions.
\end{abstract}

\section{Introduction}

Quasicrystals are physical systems which possess long-range order but without translational symmetry. The synthesis of the first quasicrystal, the metastable $\mathrm{Al}_{6} \mathrm{Mn}$ alloy by Dan Shechtman in 1982 [1] and the subsequent controversy surrounding this discovery is well-documented (e.g. [2]). In the subsequent decades many more solid quasicrystals were discovered, and a large and diverse research community came together in an effort to understand their structure, physical properties, and potential for applications [3]. Indeed, quasicrystallinity was later found in a large variety of physical systems, including dendritic liquid crystals [4], ABC-star poly-

Vincent Fournée, Julian Ledieu and Émilie Gaudry

Institut Jean Lamour, UMR 7198 CNRS et Université de Lorraine, Nancy, France e-mail: vincent.fournee@univ-lorraine.fr and Hem Raj Sharma and Ronan McGrath

Surface Science Research Centre, The University of Liverpool, Liverpool L69 3BX, UK e-mail: mcgrath@liverpool.ac.uk 
mers [5], binary nanoparticle superlattices [6], colloids [7], mesoporous silica [8], and oxide thin films [9]. New and surprising phenomena in quasicrystal systems continue to be reported; for example in 2018 the Al-Zn-Mg quasicrystal was found to be superconducting [10].

Once stable quasicrystals were discovered and produced in large enough samples [11,12], they became suitable for surface science studies. Among the first such studies were those of the ten-fold surface of the decagonal phase $[13,14]$ using scanning tunneling microscopy (STM) and low energy electron diffraction (LEED). The five-fold surfaces of icosahedral quasicrystals and the ten-fold surfaces of decagonal quasicrystals in particular have received most attention [15].

This focus on quasicrystals in turn sparked increasing focus on their approximants [16]. Approximants are periodic crystals close in stoichiometry to quasicrystals. They tend to have large unit cells and local structure within the unit cell similar to their quasicrystalline counterparts. They are attractive to study because of their periodicity - many structural (diffraction) and theoretical (density functional theory) techniques are based on a periodic formalism. Studying approximants can yield important knowledge that can be applied to the understanding of quasicrystals themselves [17]. Again, the surfaces of approximants have received considerable interest [18-20].

In time, the phrase complex metallic alloys (CMAs) began to be used to describe quasicrystals, their approximants, and other alloy structures [21] with large numbers of atoms in the unit cells. Dubois has identified the presence of a pseudogap in the electronic structure at the Fermi edge as a necessary but not sufficient differentiator between CMAs and other alloy systems [22].

Once excellent surfaces could be prepared, there followed considerable interest in the nature of epitaxial processes on CMA surfaces, and in the structure and properties of the overlayers and thin films which result [23-25]. This interest was motivated partly by the importance of thin films in technological processes, but was also curiosity-driven: would thin films and molecular overlayers adopt the structure of the substrate, or order according to the structure of the bulk? This question has been answered in part - many elements and molecules do adopt the structure of the substrate, at least in the first layer; indeed for some elements the quasicrystalline architecture persists beyond a single layer [26].

This chapter is not intended to be a comprehensive review of the literature; rather we describe a number of topics of current interest to the CMA thin film community. We discuss growth of multi-layer quasicrystalline thin films, molecular adsorption and architectures on CMA surfaces, CMAs as surface alloys and the application of CMA surfaces in catalysis. We conclude with a perspective and future look. 


\section{Growth of multi-layer quasicrystalline thin films of Ag-In-Yb surfaces}

In this section, we report studies of growth of quasicrystalline thin films of single elements on surfaces of the icosahedral (i)-Ag-In-Yb quasicrystal. All three high symmetry surfaces (2-, 3- and 5-fold) of this system have been studied [27-29] and used as a template to grow thin films of various elements such as $\mathrm{Pb}, \mathrm{Bi}$, In and $\mathrm{Sb}$. Here we will limit our discussion on the growth of $\mathrm{Pb}$ and $\mathrm{Bi}$ on the 5-fold surface $[26,30]$.

The $i$-Ag-In-Yb quasicrystal is isostructural to the binary $i$-Cd-Yb phase, where $\mathrm{Cd}$ is replaced by $\mathrm{Ag}$ and In. The atomic structure of this system can be explained by rhombic triacontahedral (RTH) cluster. The RTH cluster is formed by five successive atomic shells: a tetrahedron (innermost, $4 \mathrm{Cd}$ atoms), a dodecahedron (12 $\mathrm{Cd}$ atoms), an icosahedron (30 $\mathrm{Yb}$ atoms), an icosidodecahedron (32 $\mathrm{Cd}$ atoms) and a rhombic triacontahedron (92 Cd atoms) [31]. A RTH cluster bisected perpendicular to the five-fold axis is shown in Fig. 1(a) (first shell not shown). For clarity, we have shown different atomic shells by different colours.

Although, the three-dimensional shells are believed to be the building blocks of $i$-Cd-Yb, the structure can still be explained using a notion of atomic plane. Fig. 1(b) shows the atomic density distribution along the five-fold axis, for the ideal (unrelaxed) Cd-Yb model [31]. For simplicity, we define a region with a non-zero density as a plane. The density of the densest atomic planes is comparable to that of the closed-packed Yb surface [27]. Some of atomic planes are marked in Fig. 1(b). These planes are important for discussion of the structure of the thin films. The atomic planes are formed by atoms of specific shells of the RTH cluster. For example, plane 1 is formed by atoms of the third and fourth shells, while plane 2 is formed by atoms of the fifth shell.

When the surface of $i$-Ag-In-Yb is prepared using the common sputter-annealing methods, it produces a step-terrace structure, as revealed by scanning tunneling microscopy (STM) [27]. The terraces are formed at bulk planes intersecting the centres of the RTH clusters (for example, plane 1 in Fig. 1(b)). These surface terminating planes have a moderate atomic density. The structure of a surface terminating plane, superimposed with structure of other planes, is shown in Fig. 1(c) and (d). The structure can be mapped by a Penrose P1 tiling of edge length $2.50 \mathrm{~nm}$ with vertices located at the centres of the RTH clusters.

The atomic sites above the surface plane are vacant. Interestingly, these sites will be occupied by the adatoms ( $\mathrm{Pb}$ or $\mathrm{Bi}$ ) when deposited on the surface, mimicking the structure of RTH cluster (Fig. 1(e)). The structure of the film thus can be characterised by layers of atoms, and the structure of each layer can be deduced from the bulk structure.

Fig. 2(a) and (b) show STM images taken from first and second layer of $\mathrm{Bi}$, respectively [30]. It was found that the first layer is formed by fifth shell atoms (which form plane 5 and 6). The most common features observed in the first layer by STM are pentagonal stars, pentagons and crescent shapes (marked in Fig. 2(a)). 


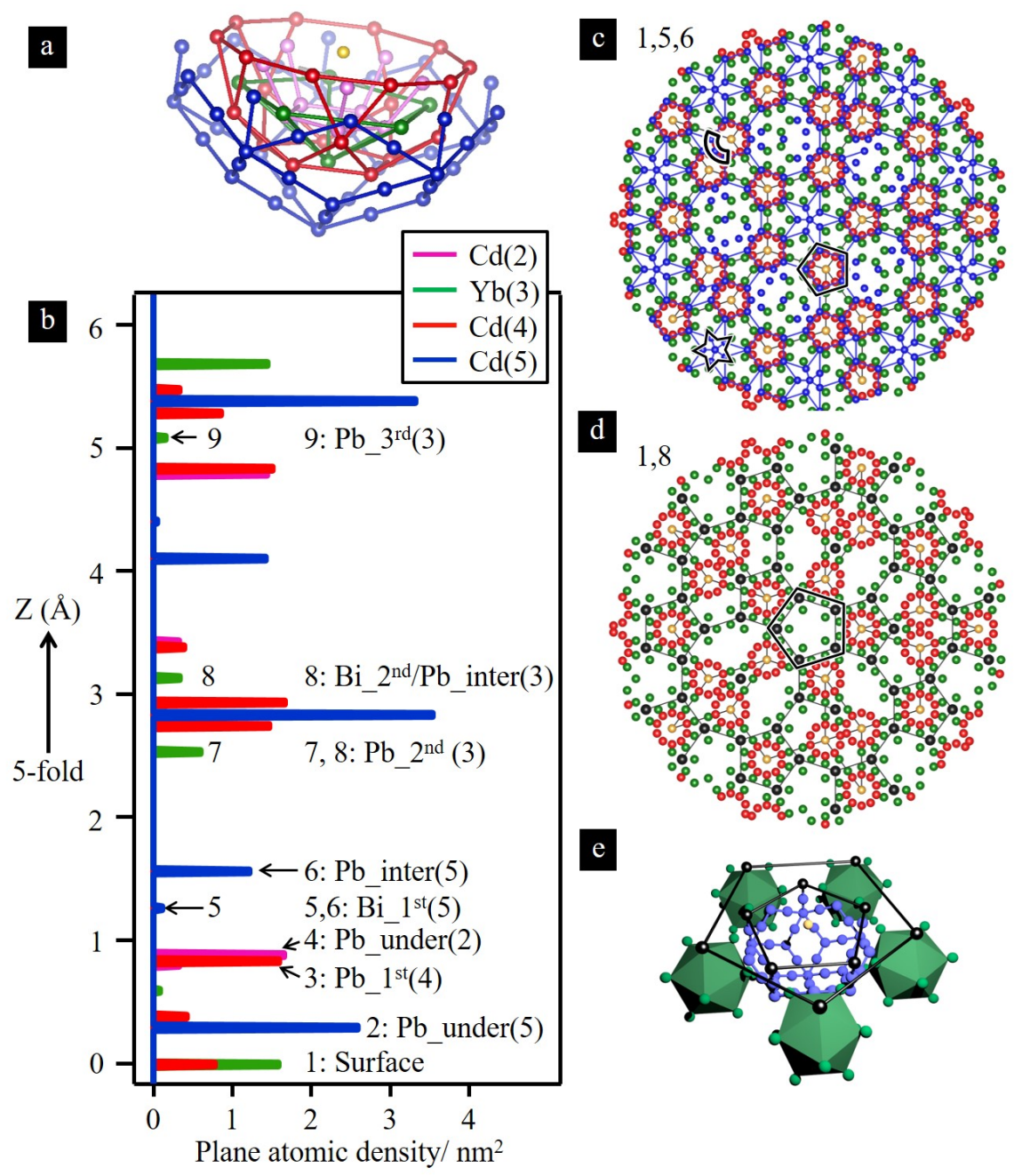

Fig. 1 (a) An RTH cluster, the building block of the $i$-Cd-Yb quasicrystal, bisected perpendicular to the five-fold axis [31]. Atoms of different shells are coloured differently. (b) Atomic density distribution along the five-fold axis deduced from the idea model structure of $i$-Cd-Yb. The density is estimated in slabs of $0.01 \mathrm{~nm}$ thickness. Plane 1 represents the surface. Other planes indicated by numbers are occupied by $\mathrm{Pb}$ or $\mathrm{Bi}$ adatoms. The number in parentheses indicates the $\mathrm{n}^{\text {th }}$ shell of the RTH cluster. (c) Structure of surface (plane 1) superimposed with planes 5 and 6, which explains the first layer of Bi. (d) Structure of surface (plane 1) superimposed with plane 8, which produces the second layer of $\mathrm{Bi}$. A Penrose P1 tiling of $2.5 \mathrm{~nm}$ edge length is superimposed in (c) and (d). (e) Surface truncated RTH clusters with Bi atoms atop. Black spheres represent Bi atoms. Only relevant shells are shown for clarity. Reprinted from [30] (C)2018 Elsevier. 
These features match very well with those in plane 5 and 6 (Fig. 1(c)), in terms of height, size, orientation and location with respect to the surface plane. Similarly, the second layer Bi atoms are located at the vertices of a Penrose P1 tiling of 2.5 $\mathrm{nm}$. This structure can be explained by $\mathrm{Yb}$ atoms of the third shell (plane 8 ). The autocorrelation pattern and the fast Fourier transform (FFT) of the STM image display ten-fold symmetry with maxima located at $\tau$-scaling distances (Fig. 2(c,d)), confirming long-range quasicrystalline order of the film. The absorption sites for Bi atoms identified by STM are similar to those established by Density functional theory (DFT) calculations [32].
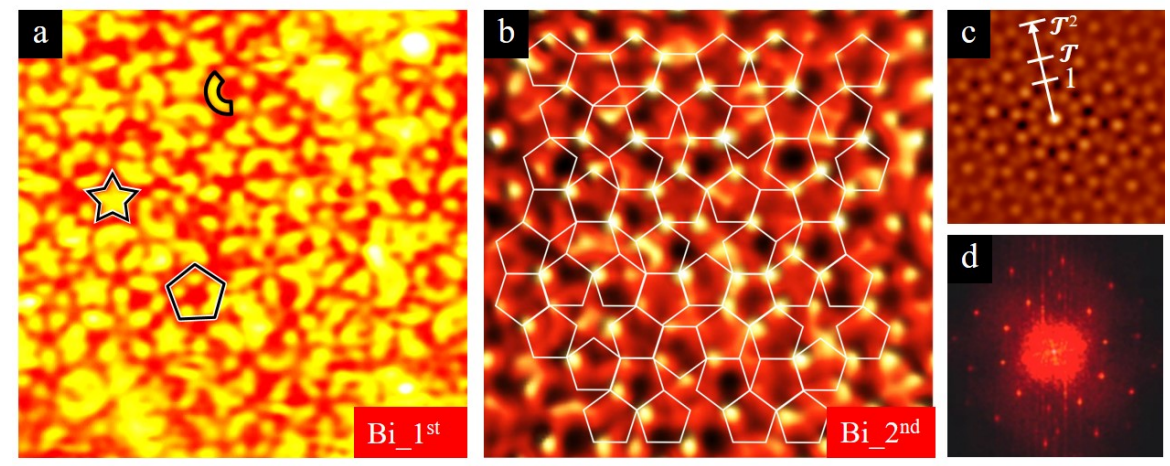

Fig. $2(a, b)$ STM images of the first layer $(20 \mathrm{~nm} \times 20 \mathrm{~nm})$ and second layer $(20 \mathrm{~nm} \times 20$ $\mathrm{nm}$ ) Bi formed on the five-fold surface of $i$-Ag-In-Yb. Common features are highlighted in (a). (c) Autocorrelation and (d) fast Fourier transform of the STM image (b). A Penrose P1 tiling of 2.5 nm edge-length is superimposed in (b). Reprinted from [30] (C)2018 Elsevier.

Lead atoms deposited on the surface also occupy the cluster sites, displaying layers of different heights. STM images of first, second and third layers of $\mathrm{Pb}$ are shown in Fig. 3(a), (b) and (c), respectively [26]. These layers are formed at planes 2 (fourth shell), 7/8 (third shell) and 3 (third shell), respectively. DFT calculations have identified other layers, denoted by $\mathrm{Pb} \_$under and $\mathrm{Pb}$ _inter in Fig. 1(b) [26]. The $\mathrm{Pb} \_$under layer, which is underneath the first layer, is formed after the first layer is completed and thus this layer is not observed by STM. The existence of these under- and intermediate-layers is vital for the stability of the other layers, and thus the film as a whole. The formation of layered structure is also confirmed by x-ray photoemission spectroscopy (XPS) [26].

The atomic density of a single layer is very low such that the distance between $\mathrm{Pb}$ atoms in the layer is larger than the nearest neighbour distance of $\mathrm{Pb}$ in its natural face-centred cubic structure. However, the $\mathrm{Pb}-\mathrm{Pb}$ distance in neighboring layers is short enough (comparable to the fcc $\mathrm{Pb}-\mathrm{Pb}$ distance) to have a strong interaction between the adatoms, stabilizing such 3D films [26]. The same observation is true for Bi films [30]. 

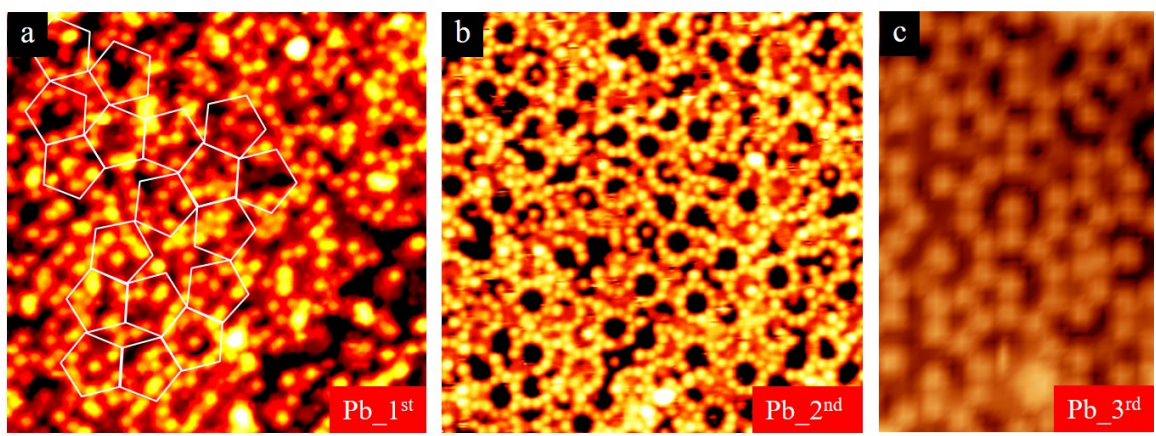

Fig. 3 (a-c) STM images of the first $(30 \mathrm{~nm} \times 30 \mathrm{~nm})$, second $(20 \mathrm{~nm} \times 20 \mathrm{~nm})$ and third $(23 \mathrm{~nm}$ $\times 15 \mathrm{~nm}$ ) layer $\mathrm{Pb}$ formed on the five-fold surface of $i$-Ag-In- $\mathrm{Yb}$ [26]. A Penrose P1 tiling of 2.5 nm edge-length is superimposed in (a).

The nature of thin film growth on $i$-Ag-In- $\mathrm{Yb}$ is unique. A certain number of elements $(\mathrm{Pb}, \mathrm{Bi}, \mathrm{Sb}$ and $\mathrm{Sn})$ grown on $\mathrm{Al}$-based quasicrystals are also found to develop quasicrystalline structure. However, quasicrystalline order is limited up to one atomic layer [33-36], in contrast to three-dimensional quasicrystalline growth on $i$-Ag-In- $\mathrm{Yb}$. After completion of the monolayer, the adsorbate develops its natural periodic structure [37,38], [39]. Some other systems, for example $\mathrm{Cu}$ or $\mathrm{Co}$ on the $i$-Al-Pd-Mn surface, yields atomic rows spaced in a Fibonacci sequence at coverage above a few atomic layers [40-42]. Below this critical coverage, no order is observed. The structure within the atomic rows is periodic.

\section{Intermetallic surfaces as templates for complex molecular architectures}

The formation of molecular thin films on metal surfaces typically occurs out of thermodynamic equilibrium. It involves molecular adsorption from the gas phase to the surface, random diffusion of the molecules between local minima of the potential energy surface (which is a thermally activated process to overcome surface diffusion barriers), and island nucleation or attachment to a pre-existing island. If the deposition flux is high and the substrate temperature is low, the diffusivity of the molecules is low and they will be easily trapped into metastable adsorption sites or captured by pre-existing nuclei. In this case, the corrugation of the potential energy surface cannot efficiently drive the molecular self-assembly. On the other side, if the deposition flux is low and the substrate temperature is high, then diffusivity of the molecules is high and the molecules can more easily explore the potential energy surface and reach the deepest adsorption sites before nucleating into islands. These deposition 
conditions are therefore more favorable to take benefit from the templating effect of the substrate and drive molecular self-assembly into long-range ordered structure.

First attempts to grow molecular films on quasicrystalline surfaces were performed by room temperature deposition of fullerene $\mathrm{C}_{60}$ on the 5-fold surface of the icosahedral Al-Pd-Mn quasicrystal [43] or the 10-fold surface of the decagonal Al-Ni-Co quasicrystal [44]. STM images of these surfaces dosed with a fraction of a monolayer showed individual immobile molecules rather than the formation of islands, suggesting that the molecules are trapped in adsorption sites and cannot diffuse further at this temperature. Nevertheless, common distances separating individual molecules were found to exhibit $\tau$ scaling relationships characteristic of the bare quasicrystalline substrate, suggesting that local ordering takes place at low coverage. However, upon further deposition, a disordered film is obtained producing no diffraction pattern. Post-annealing treatment of the as-deposited films did not produce any structural change and the molecules were found to desorb above $600 \mathrm{~K}$.

Two recent studies reported the growth of ordered quasiperiodic $\mathrm{C}_{60}$ films templated on quasicrystalline substrates obtained after high temperature deposition $[45,46]$. Smerdon et al. [45] reported the growth of a $\mathrm{C}_{60}$ film deposited on the fivefold surface of the $\mathrm{Al}-\mathrm{Cu}-\mathrm{Fe}$ icosahedral quasicrystal held at a temperature comprised between 770 and $970 \mathrm{~K}$. In this temperature regime, a complete monolayer cannot be obtained due to a reduced sticking coefficient and/or possible molecular desorption taking place. STM investigations of the film revealed individual molecules trapped in a set of deeper adsorption sites and forming a discontinuous film (see Fig.4(a)). The fast-Fourier transform and autocorrelation function of the position map of individual $\mathrm{C}_{60}$ exhibited a ten-fold rotational symmetry and $\tau$ scaling relationships characteristic of quasiperiodic systems (see Fig.4(b)). Some of the molecules appeared brighter than others, corresponding to a height difference of 1.4 $\AA$ with respect to dimer molecules. It was concluded that this height difference is due to molecules adsorbed at two different types of adsorption sites. The complete analysis of the STM images led to a scenario in which bright $\mathrm{C}_{60}$ molecules partially occupy a pentagonal lattice with edge length equal to $1.2 \mathrm{~nm}$ connecting Fe surface atoms embedded in an otherwise almost pure $\mathrm{Al}$ top layer [47]. The dim molecules were ascribed to $\mathrm{C}_{60}$ adsorbed on top of subsurface $\mathrm{Fe}$ atoms located at about 2.1 $\AA$ below the top plane, implying some surface reconstruction.

Another study reported the growth of dense, long-range quasiperiodically ordered $\mathrm{C}_{60}$ layers grown on various quasicrystalline surfaces held between 623 and $673 \mathrm{~K}$ [46]. This temperature range is still above the multilayer desorption temperature but low enough to allow saturation of the first layer. It is high enough to facilitate molecular diffusion and sampling of the potential energy surface and still low to avoid fragmentation or polymerization of the $\mathrm{C}_{60}$ as verified by core-level photoemission spectroscopy. Molecular films were grown on the five-fold surfaces of $\mathrm{Al}$ $\mathrm{Pd}-\mathrm{Mn}$ and $\mathrm{Al}-\mathrm{Cu}-\mathrm{Fe}$ icosahedral quasicrystals as well as on the ten-fold surfaces of the $\mathrm{Al}-\mathrm{Cu}-\mathrm{Co}$ and $\mathrm{Al}-\mathrm{Ni}-\mathrm{Co}$ decagonal quasicrystals. The long-range quasiperiodic order was demonstrated by the LEED patterns exhibiting sharp diffraction spots 


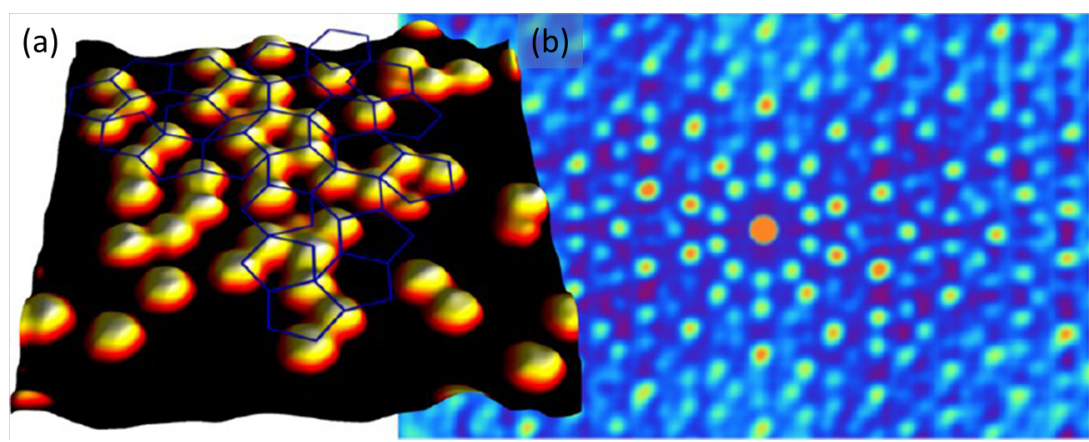

Fig. 4 (a) STM image $\left(11 \times 13 \mathrm{~nm}^{2}\right)$ showing individual $\mathrm{C}_{60}$ molecules deposited on the 5-fold surface of the i-Al-Cu-Fe. They are located at the node of a quasiperiodic tiling. (b) autocorrelation pattern of the position map of the molecules extracted from an STM image, showing 10-fold symmetry of the layer. Adapted with permission from J. A. Smerdon, K. M. Young, M. Lowe, S. S. Hars, T. P. Yadav, D. Hesp, V. R. Dhanak, A. P. Tsai, H. R. Sharma, and R. McGrath, Nano Letters 14, 1184 (2014). Copyright (2014) American Chemical Society.

and either five- or ten-fold rotational symmetry. Fast-Fourier transform and autocorrelation of STM images are characterized by rings of ten spots with diameters related by $\tau$ scaling relationships, in agreement with the LEED patterns. The structure of the film can be interpreted by the adsorption of the molecules at specific sites of the substrate exhibiting a local five-fold symmetry. Both decagonal phases are described by the packing of partially overlapping columnar clusters extending along the ten-fold axis, perpendicular to the surface plane (see Fig.5). The cluster centers truncated by the surface constitute five-fold symmetric sites located at the nodes of a quasiperiodic tiling made of pentagonal (P), star (S) and boat (B) tiles, with an edge length equal to $2 \mathrm{~nm}$ [48]. Additional five-fold symmetric sites form inverted pentagons with edge length equal to $1.2 \mathrm{~nm}$ inside the $\mathrm{P}$ tiles. The decoration of these specific sites with $\mathrm{C}_{60}$ perfectly reproduces the experimentally observed film structure. It leads to a dense molecular film, with a packing density of one $\mathrm{C}_{60}$ per $\mathrm{nm}^{2}$ and the shortest intermolecular distances of about $1 \mathrm{~nm}$, i.e. similar to the van der Waals radius. The molecules have different contrasts in the STM images, corresponding to an height difference of 0.1 to $0.2 \mathrm{~nm}$, but these values are strongly bias dependent suggesting some electronic origin. It may be due to differences in the local chemistry surrounding the various adsorption sites and/or to different adsorption configuration of the molecules.

A similar self-assembly occurs for $\mathrm{C}_{60}$ deposited on the five-fold surfaces of $\mathrm{Al}-\mathrm{Cu}-\mathrm{Fe}$ and $\mathrm{Al}-\mathrm{Pd}-\mathrm{Mn}$ icosahedral phases, leading to dense molecular films with long-range quasiperiodic order. In these cases, the molecules appear either bright or dim at negative bias in STM images, corresponding to a height difference of about $0.1 \mathrm{~nm}$. The most common motifs are $1.2 \mathrm{~nm}$ edge-length pentagonal tiles made by five bright $\mathrm{C}_{60}$ centered by either a bright or a dim molecule. These bright and 


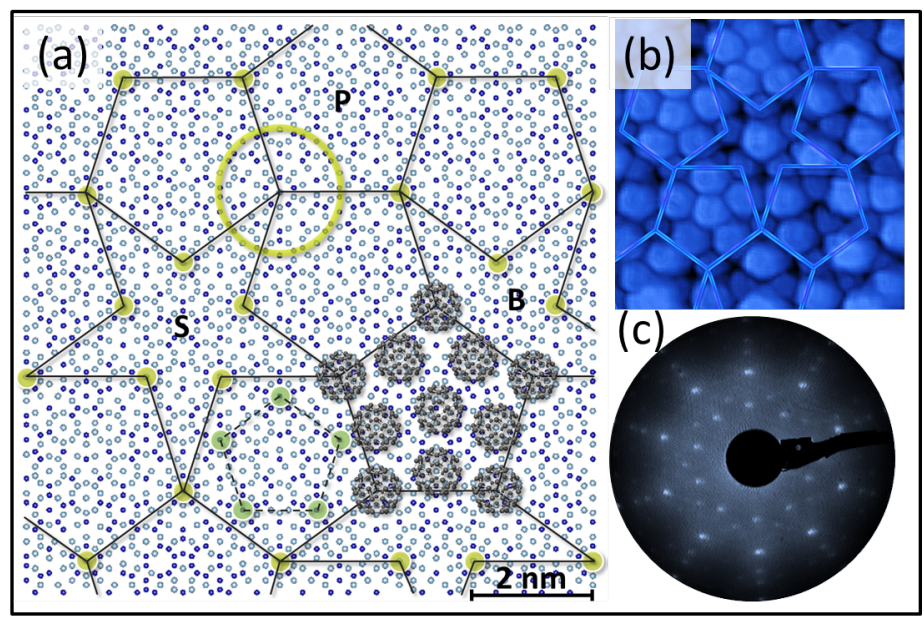

Fig. 5 (a) Structure model of the d-Al-Cu-Co decagonal phase perpendicular to the 10-fold axis. $\mathrm{Al}$ atoms appear as light blue circles and transition metal atoms $(\mathrm{Cu} / \mathrm{Co})$ as dark blue circles. The cluster centers are highlighted as yellow circles. The yellow ring delimits the $2 \mathrm{~nm}$ wide cluster units. The tiling connecting the cluster centers appears as dark lines. It consists in pentagonal $(\mathrm{P})$, star (S) and boat (B) tiles with $2 \mathrm{~nm}$ edge length. The green circles inside the $\mathrm{P}$ tile at the bottom of the figure indicate additional five-fold symmetric sites. They define a smaller pentagon with edge length $1.2 \mathrm{~nm}$ (dotted dark line). The decoration of the $\mathrm{P}$ tile by $\mathrm{C}_{60}$ molecules (in grey) is illustrated. (b) A portion of the quasiperiodic tiling with $2 \mathrm{~nm}$ edge length superimposed on an STM image of the $\mathrm{C}_{60}$ film. (c) LEED pattern of the $\mathrm{C}_{60}$ film formed on that surface, recorded at a primary beam energy of $48 \mathrm{eV}$. Adapted from [46].

dim motifs are pointing in opposite direction on a same terrace and they keep the same orientation across terraces. The structure of the films can again be explained by preferential adsorption at specific sites of the substrate characterized by a local five-fold symmetry. Both icosahedral phases are described as a packing of pseudoBergman and pseudo-Mackay type clusters. The surface terminations of both phases correspond to dense Al-rich planes of the bulk structure. The most frequent motifs observed by STM have been termed 'white flowers' (WF) and 'dark stars' (DS). They both correspond to truncated clusters or clusters hanging down from the surface plane, but the DS motifs have a central vacancy. Both motifs exhibit local fivefold symmetry. The WF are located at the nodes of a tiling made of pentagons, stars and rhombi with an edge length equal to $1.26 \mathrm{~nm}$ [49-51]. Some of the pentagonal tiles have a DS motif in their interior, all pointing in the same direction. It was thus concluded that the molecular self-assembly occurs through preferential adsorption of the $\mathrm{C}_{60}$ at these specific sites, the dim molecules corresponding to $\mathrm{C}_{60}$ adsorbed at DS sites, i.e. on top of a vacancy. This growth scenario perfectly matches with all experimental observations. It was further verified by performing submonolayer deposition experiments, allowing to image both the substrate structure and the $\mathrm{C}_{60}$ positions in order to determine the adsorption sites. 
For both icosahedral and decagonal substrates, the driving force promoting the molecular self-assembly is the preferential adsorption at specific sites exhibiting local five-fold symmetry. Considering that symmetry matching between the molecules and the substrate is an important factor in determining the adsorption configuration, these results suggest that the molecules adsorb with a $\mathrm{C}$ pentagonal face down at these five-fold symmetric sites. Ab initio DFT calculations DFT have then been performed in the case of $\mathrm{C}_{60} / \mathrm{Al}-\mathrm{Pd}-\mathrm{Mn}$ in order to determine adsorption energies of $\mathrm{C}_{60}$ molecules at different adsorption sites and for various adsorption configurations. These calculations were performed using a structure model of a periodic approximant which contains both the WF and DS local configurations. The most stable adsorption configurations were found to correspond to $\mathrm{C}_{60}$ contacting the surface with a pentagonal face aligned with the five $\mathrm{Al}$ atoms forming the DS motif or aligned with $\mathrm{Al}$ pentagon centered by a Mn atom for the WF motif. The DFT calculations indicate that the bonding is quite different at DS and WF sites. At DS sites, the bonding is rather directional between the $5 \mathrm{C}-\mathrm{Al}$ pairs. The $\mathrm{C}$ atoms involved are not those forming the bottom pentagonal face but are $\mathrm{C}$ atoms involved in adjacent hexagonal faces. At WF sites, the bonding charge is localized at the interface between the pentagonal $\mathrm{C}$ face and the Mn atom at the center of the WF motif. The calculated densities of states show a broadening of the molecular orbitals as well as an energy shift consistent with a charge transfer from the substrate to the molecules. New electronic states appear at the Fermi level as a result of $s p$ and spd hybridization between $\mathrm{C}$ and substrate atoms, the film becoming metallic. It is to be noted that $\mathrm{C}_{60}$ adsorption with a $\mathrm{C}$ pentagonal face contacting the surface is rather unusual compared to noble metal surfaces but maybe quite general for quasicrystalline substrates or possibly their approximants due to the existence of local five-fold symmetric configuration.

Additional growth experiments have been reported using different types of molecular building blocks. One is the growth of corannulene $\mathrm{C}_{20} \mathrm{H}_{10}$ on the fivefold surface of the Ag-In- $\mathrm{Yb}$ quasicrystal at room temperature [52]. Corannulene molecules are bowl-shape, consisting of a fragment of a $\mathrm{C}_{60}$ and they have $\mathrm{C}_{5 v}$ symmetry. This system also self-assembles into a quasiperiodic pattern which appears to be driven again by symmetry matching, in the sense that the specific adsorption sites identified are characterized by their local five-fold symmetry.

A totally different picture was found for pentacene molecules deposited on the same surface [45]. Pentacene are polycyclic aromatic hydrocarbon molecules consisting of five linearly-fused benzene rings; it is an organic semiconductor. The room temperature diffusivity of the pentacene was found high enough to lead to a quasiperiodic distribution of the molecules as demonstrated by the autocorrelation function of the molecular positions map. Pentacene molecules do not have five-fold symmetry contrary to $\mathrm{C}_{60}$ and therefore symmetry matching between molecules and substrate does not play a significant role. From the analysis of the STM data, it was concluded that pentacene molecules are anchored on pairs of $\mathrm{Yb}$ surface atoms, which are quasiperiodically distributed. Therefore the chemical affinity between the 
molecules and the various species present in the surface planes is the key factor driving the self-assembly in this particular case.

In conclusion, quasicrystalline surfaces are both structurally and chemically complex and they have been used successfully as templates for the self-assembly of molecular building blocks into quasiperiodically ordered thin films. So far, mainly prototype molecules like $\mathrm{C}_{60}$ have been used, but there is a full range of more complex molecules carrying various functional properties awaiting for further growth experiments. These are considered as interesting model systems to understand the structure/properties relationship linked to the long-range quasiperiodic order.

\section{Complex intermetallics as surface alloys: an alternative}

Most of the structural work performed on complex intermetallic surfaces have been achieved using centimeter-sized single crystals of high structural quality and purity. Such specimens can be obtained by conventional growth techniques. Once pol-

ished and oriented, they are investigated using surface science techniques under ultra high vacuum conditions. Depending on the intermetallics targeted, it is not always possible to obtain large enough samples due to for instance growth limitations (temperature, phase diagram constraints ...) or elemental costs. Hence, an alternative approach consists in the deposition of pure elements on unary, binary or even ternary systems aiming to form the desire complex phases as surface alloys. The crystallographic and electronic surface structures of the terminating layers can then be characterised in situ. Sometimes the growth of surface intermetallic compounds can be fortunate originating from the alloying between adsorbates and substrate elements. As will be described below, this has often occurred while studying the growth of atomic thin films on aperiodic systems [53-57].

Elemental adsorption on a binary intermetallic compound represents also a great opportunity to follow the initial nucleation and growth of complex metallic alloys, including the propagation of aperiodic long-range order. In addition to the determination of the clean surface structure, the formation of complex intermetallic compounds as surface alloys allows characterisation down to the atomic level of the interfaces between the matrix (here the substrate) and the grown phase. Such fundamental studies could in fine bring new solutions to issues encountered in the field of coating technology. Regarding complex metallic alloys, we will refer here to delamination and reactive diffusion upon post-annealing treatment often identified as technological bottlenecks [58]. Hence, an atomistic description of the interfacial structure between both antagonists could lead to the design of specific buffer layers to accommodate the strain related to lattice mismatch and/or to release internal stress due to thermal expansion coefficient differences between the two phases.

Although extensive works on single and multilayer surface alloys have been reported [59], the surface characterisation of Al-based (complex) intermetallic compounds formed upon adsorption is much more limited. We will start with studies 
where intermetallic compounds have been formed while trying to grow quasiperiodic thin films.

Due to its tendency to self-assemble into decagonal and icosahedral shaped clusters, the adsorption of $\mathrm{Au}$ atoms was carried out on the decagonal Al-Ni-Co surface [53]. Submonolayer deposition of Au adatoms at room temperature leads to the formation of a Al-Au surface alloy without any orientational order as evidenced from x-ray photoelectron diffraction (XPD) and reflection high-energy electron diffraction (RHEED) experiments. Upon annealing the dosed sample to 350-400 $\mathrm{K}$, the surface structure changes and can be interpreted as an epitaxial layer consisting of twinned $\mathrm{Au}-\mathrm{Al}_{2}$ crystals with (110)-oriented surface (see Fig.6(a)) [53 ${ }^{1}$. The twin azimuthal orientations replicate the ten-fold symmetry of the underlying template. For $10 \mathrm{ML}$ thick Au layers, the thin film is described as a polycrystalline Au layer using RHEED measurements. The structure is unchanged upon annealing the Au thick film until adatom re-evaporation occurs [55]. The same scenarios apply to Au adsorption on the five-fold Al-Pd-Mn surface [54] and for Pt adsorption on the decagonal Al-Ni-Co surface with the formation of a Pt polycrystalline film regardless of the film thickness [60]. However, the Au and Pt growth modes are altered if the quasicrystalline substrate is pre-covered by an In layer $[54,55,60]$. Indeed, the Au polycrystalline thick film deposited at room temperature on the In pre-covered surface transforms upon annealing to $350-400 \mathrm{~K}$ to the $\mathrm{AuAl}_{2}$ structure as demonstrated by RHEED and X-ray photoelectron spectroscopy (XPS) analysis. As already observed for submonolayer deposition [53], XPD images reveal a tenfold symmetry pattern consistent with an epitaxial layer model of multiply twinned $\mathrm{AuAl}_{2}$ (110)-oriented crystals [55]. Based on XPS analysis, there is clear evidence for In diffusion across the thick Au overlayer at $300 \mathrm{~K}$. With annealing, the initial In $3 d$ core level intensity is restored. Indium is then considered here as a surfactant promoting Frank-van der Merwe over Stranski-Krastanov type growth. Similar mechanisms are observed while dosing $\mathrm{Pt}$ and $\mathrm{Au}$ adatoms on In pre-covered $\mathrm{Al}-$ $\mathrm{Ni}-\mathrm{Co}$ and $\mathrm{Al}-\mathrm{Pd}-\mathrm{Mn}$ surfaces respectively. In the former case, the structure of the annealed Pt thick film $(490 \mathrm{~K})$ results in an epitaxial layer of multiply twinned Pt$\mathrm{Al}_{2}$ crystals [60].

Still aiming at forming pseudomorphic overlayers, another intermetallic phase has been grown on similar quasicrystalline substrates. Located in the same column of the Periodic Table as $\mathrm{Au}$, the adsorption of $\mathrm{Cu}$ atoms on complex metallic alloy surfaces has led to the formation of a unique intermetallic compound, namely the complex Hume-Rothery $\mathrm{Al}_{4} \mathrm{Cu}_{9}$ phase. The lattice parameter of this simple cubic $\gamma$-brass phase is equal to $8.71 \AA$ (space group $P \overline{4} 3 m$ ). At room temperature, the adsorption of $\mathrm{Cu}$ adatoms on the five-fold and two-fold Al-Pd-Mn quasicrystalline surfaces yields quasiperiodic structures [40,61]. Once annealed to $570 \mathrm{~K}$, the thick $\mathrm{Cu}$ film (25 ML) crystallises into five periodic domains rotated from each other by $72^{\circ}$, i.e. following the directional order of the five-fold substrate [56]. XPS, XPD and LEED analysis reveal that the domains correspond to the (110) surface-oriented $\mathrm{Al}_{4} \mathrm{Cu}_{9}$ structure [57]. This is also the conclusion drawn when $\mathrm{Cu}$ adsorption is car-

${ }^{1}$ The term "epitaxy" refers here to situation where films grown on quasicrystalline surfaces preserve the substrate directional order. 
ried out on the five-fold $\mathrm{Al}-\mathrm{Cu}-\mathrm{Fe}$ surface. Contrary to the $\mathrm{Cu} / \mathrm{Al}-\mathrm{Pd}-\mathrm{Mn}$ system, the formation of $\beta-\mathrm{Al}(\mathrm{Cu}, \mathrm{Fe})(110)$ domains is initially observed at room temperature from $1 \mathrm{ML}$ to $8 \mathrm{ML}$ [62]. Within this coverage regime, the $\beta$-phase is also the stable phase up to $573 \mathrm{~K}$. Then, the growth of five $\mathrm{Al}_{4} \mathrm{Cu}_{9}(110)$ domains appears for 20 ML thick $\mathrm{Cu}$ film annealed to $558 \mathrm{~K}$, i.e. there is a minimal $\mathrm{Cu}$ thickness required to growth the $\mathrm{Al}_{4} \mathrm{Cu}_{9}$ phase as a surface alloy.

Interestingly, this $\gamma$-brass phase is also the one that appears upon the adsorption of $\mathrm{Al}$ atoms on a simple $\mathrm{Cu}(111)$ surface. In this case, the formation of $\mathrm{Al}_{4} \mathrm{Cu}_{9}(110)$ domains occurs only if the nominal Al thickness is above 12 ML. The STM measurements combined with ab initio calculations demonstrate that the $\gamma-\mathrm{Al}_{4} \mathrm{Cu}_{9}$ surface is bulk-terminated at puckered planes [63]. This conclusion is in agreement with the surface plane selection identified across the $\mathrm{Al}_{4} \mathrm{Cu}_{9}(110)$ surface using a single crystal [64].

As explained at the beginning of this section, elemental adsorption on a binary complex metallic alloy could represent an alternative route to grow ternary quasiperiodic surface phases and to possibly monitor in situ the propagation of long range order. To this end, $\mathrm{Cu}$ adatoms have been deposited on the $\mathrm{Al}_{13} \mathrm{Co}_{4}(100)$ surface [65]. The latter crystal which is considered as an approximant to the decagonal quasicrystal, was an apparently ideal candidate for aperiodic surface alloy formation. Instead, the results indicate the formation of a $\beta-\mathrm{Al}(\mathrm{Cu}, \mathrm{Co})$ phase above 3 $\mathrm{ML} \mathrm{Cu}$ deposition at $300 \mathrm{~K}$. For higher temperature (473 K), the $\beta-\mathrm{Al}(\mathrm{Cu}, \mathrm{Co})$ is also formed but it is replaced by a $\gamma-\mathrm{Al}_{4} \mathrm{Cu}_{9}$ phase above $7.5 \mathrm{ML} \mathrm{Cu}$ deposition [65]. One of the striking features lies here in the domain orientations of both $\beta$ and $\gamma$-phases. The orientation of the $\gamma-\mathrm{Al}_{4} \mathrm{Cu}_{9}$ domains reported in previous studies tends to match with the atomically densest directions of the surface plane. Hence, five domains and two sets of three-fold rotational domains are formed on five-fold surfaces and on $\mathrm{Cu}(111)$ respectively. For the $\mathrm{Cu} / \mathrm{Al}_{13} \mathrm{Co}_{4}(100)$ case, the two (110) domains identified across the surface are rotated from each other by $72^{\circ}$. Moreover, the growth proceeds $4 \pm 1^{\circ}$ off the [011] and [011] directions of the orthorhombic substrate. At this stage, these peculiar growth directions could only be related to the orientation of the bipentagonal motifs present on the clean $\mathrm{Al}_{13} \mathrm{Co}_{4}(100)$ surface. These motifs correspond to the elementary pentagonal bipyramid clusters, i.e. building blocks of the bulk structure. These different studies demonstrate the stability of the $\gamma-\mathrm{Al}_{4} \mathrm{Cu}_{9}$ phase as a surface alloy. It also shows that the phase will be formed as long as a critical amount of $\mathrm{Al}$ and $\mathrm{Cu}$ elements is reached within the surface region. The surface structural complexity has little influence on the $\gamma-\mathrm{Al}_{4} \mathrm{Cu}_{9}$ phase growth except for the domain orientations.

Aside from model adsorption studies performed under ultra high vacuum conditions, the formation of complex intermetallic compounds is also encountered in industrial processes. To improve their oxidation and corrosion resistance, steel and cast iron can be hot-dip coated with pure $\mathrm{Al}$ or $\mathrm{Al}$ alloys of varying composition. The resulting coating which is dependent on the chemical composition of the bath consists of an outer layer and an inner intermetallic layer which can be further subdivided in two zones. Using a pure $\mathrm{Al}$ bath, the intermetallic layer adjacent to the cast iron (first zone) contains the $\mathrm{Al}_{5} \mathrm{Fe}_{2}$ phase while in the second zone the $\mathrm{Al}_{3} \mathrm{Fe}$ 
is identified ( $\mathrm{Si}$ atoms being present in both phases in different amounts) [66]. The resulting interfaces between the different antagonists vary quite drastically from an irregular tongue-like morphology between the cast iron and the $\mathrm{Al}_{5} \mathrm{Fe}_{2}$ layer to a more regular interface between the $\mathrm{Al}$ outer layer and the $\mathrm{Al}_{3} \mathrm{Fe}$ phase. The interfacial microstructure and composition will in fine dictate the coating physical and chemical properties.

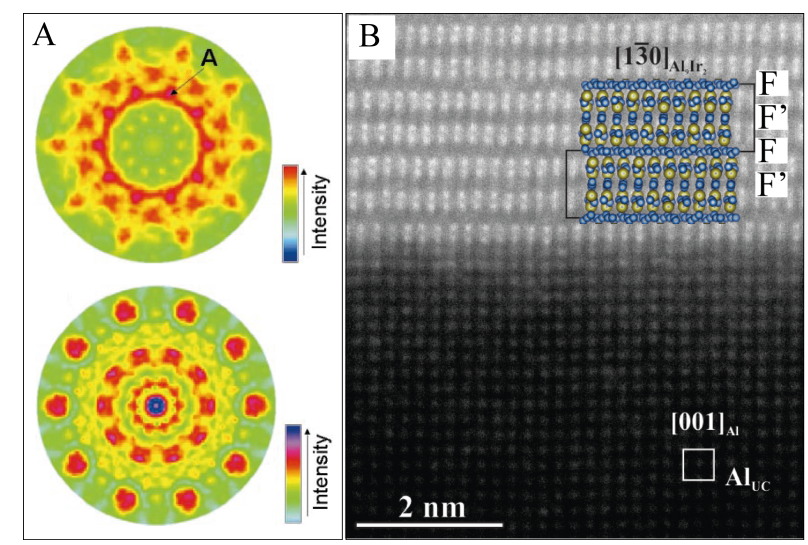

Fig. 6 (a) Stereographic projection (top) and single scattering cluster simulations (bottom) XPD images for $\mathrm{Au} 4 f$ from the Au-dosed and annealed decagonal Al-Ni-Co surface and from an epitaxial $\mathrm{AuAl}_{2}$ layer respectively. (b) Atomically resolved HAADF-STEM image of the precipitate/matrix interface with the superimposed structural units of $\mathrm{Al}_{9} \mathrm{Ir}_{2}$ and $\mathrm{Al}$ substrate viewed in the $[1 \overline{3} 0]_{A l_{9} I r_{2}}$ and $[001]_{A l}$ projections respectively. ((a) Reprinted with permission from [53] M. Shimoda, T. Sato, A. Tsai, J.Q. Guo, Phys. Rev. B, 62, 11288 (2000), https://doi.org/10.1103/PhysRevB.62.11288, copyright (2000) by the American Physical Society, and (b) reprinted with permission from [67] J. Kadok, K. Pussi, S. Šturm, B. Ambrožič, É. Gaudry, M.C. de Weerd, V. Fournée, J. Ledieu, Physical Review Materials 2(4), 043405 (2018), https://doi.org/10.1103/PhysRevMaterials.2.043405, copyright (2018) by the American Physical Society.

Depending on the applications, protective coatings may be designed to sustain harsh conditions, including for instance high temperature conditions and/or excessive oxidizing environments. Given its high melting temperature and due to its oxidation resistance, Al-Ir based coating have been considered as protective coating in gas turbine engines [68]. Although several methods are focussing on improving deposition processes, little is know on the surface structure of Al-Ir alloys and compounds. This is true for the interfacial structure between Al-Ir and the supporting substrate also.

To this end, the adsorption of $\mathrm{Ir}$ atoms on the $\mathrm{Al}(100)$ clean surface has been recently carried out under ultra high vacuum conditions. The objectives were to determine (i) which Al-Ir phases will initially appear; (ii) the associated surface 
structure ${ }^{2}$ and (iii) the corresponding interface structure between the single crystal and the surface alloys formed. A reverse strategy by adsorbing Al on $\operatorname{Ir}(111)$ surface had been previously chosen to study the Ir-rich side of the phase diagram [69]. The layer-by-layer growth mode reported at $300 \mathrm{~K}$ preceded the formation of $\operatorname{Ir}_{4} \mathrm{Al}$ surface aluminide obtained for high temperature deposition (1100 K to $1500 \mathrm{~K}$ ). For the $\mathrm{Ir} / \mathrm{Al}(100)$ system, a higher intermixing length is already expected at room temperature [70]. This is confirmed by experimental and theoretical results revealing diffusion of Ir adatoms within the surface selvedge at room temperature [67]. Ir adsorption above $623 \mathrm{~K}$ leads to the growth of Al-Ir domains exhibiting an unit cell equal to $\sqrt{5}$ times the $\mathrm{Al}(100)$ surface unit cell. After a careful analysis of the Al-Ir binary system and in agreement with dynamical LEED analysis, the grown phase has been assigned to the $\mathrm{Al}_{9} \mathrm{Ir}_{2}$ compound. The surface of the $\mathrm{Al}_{9} \operatorname{Ir}_{2}(001)$ oriented domain is bulk-terminated at pure $\mathrm{Al}$ planes in accordance with ab initio calculations demonstrating that Ir adatoms located within the topmost surface layer are energetically unfavored.

Regarding the $\mathrm{Al}_{9} \mathrm{Ir}_{2}$ growth orientation with respect to the $\mathrm{Al}(100)$ substrate, it can be described for one domain by the following epitaxial relation: $(100)_{A l}[001]_{A l}$ $\|(001)_{A l_{9} I r_{2}}[1 \overline{3} 0]_{A l_{9} I r_{2}}$

As shown using STM, LEED and transmission electron microscopy (TEM) techniques, these specific domain orientations originate from the alignment of local $\mathrm{Al}$ motifs present in the $\mathrm{Al}_{9} \mathrm{Ir}_{2}(001)$ planes with the $\mathrm{Al}(100)$ surface unit cell. Atomicresolution high-angle annular dark field scanning TEM (HAADF-STEM) images reveal a coherent growth and a sharp interface between $\mathrm{Al}_{9} \mathrm{Ir}_{2}$ precipitates and the Al matrix (see Fig.6(b)) [67]. The absence of dislocations within the measurements is related to the low strain due to lattice mismatches close to $0.4 \%$ between the two antagonists.

From the work presented in this section, it is clear that the surface characterisation of complex intermetallic grown as surface alloys is still in its infancy. It is also true for interfacial structural characterisation, which should play a crucial role when intermetallic compounds are envisaged as protective or functionalised coating. Furthermore, the introduction of intermetallic phases as buffer layers between substrates and coatings may represent an interesting alternative to circumvent adhesion or delamination issues [62].

\section{Complex intermetallic surfaces and recent developments in catalysis}

The interest in (complex) intermetallics as catalysts has increased significantly in the past few years, as documented in recent numerous reviews [71-74]. Indeed, their surfaces present several main advantages compared to simple metals and alloys. They are stable, with surface segregation being generally suppressed, due to

\footnotetext{
${ }^{2}$ The Ir cost prohibited the growth of a large single crystal here.
} 
the strong bonding network occurring in the bulk materials. Site isolation, i.e. the spatial separation of catalytically active sites at the surface, is commonly achieved on complex intermetallic surfaces, which is known to be an important factor for reaction selectivity. Synergistic effects are also expected when combining different chemical elements in ordered alloys, like the ones highlighted using PdZn and $\mathrm{PdCd}$ as selective catalysts for methanol steam reforming [75,76]. While pure $\mathrm{Cu}$ is traditionally used for this reaction, PdZn and PdCd lead to similar high selectivity towards the formation of $\mathrm{CO}_{2}$. It is attributed to the similar valence electronic densities of states of $\mathrm{Cu}$ and the 1:1 compounds. PdZn and PdCd can then be considered as replacing $\mathrm{Cu}$ for this reaction.

Due to the large number of intermetallic compounds known so far - more than 6000 binaries have been synthesized and characterized up to now, one expects to find new competitive intermetallic catalysts by a careful selection of their atomic and electronic surface structures. Several families of intermetallics have already been identified as stable, reactive and selective catalysts. Most of them combines noble metals - the catalytically active sites - with elements from different areas of the periodic table, for example, $s p$ metals like $\mathrm{Al}, \mathrm{Ga}$ or $\mathrm{Sn}$. A few noble metal-free catalysts do exist, promising for the reduction of costs and environmental impacts.

In the following sub-sections, two families of (complex) intermetallic compounds are discussed, in relation to the hydrogenation of acetylene and butadiene. The case of quasicrystals or approximants used as catalysts after a leaching process [77-82] is not developed, since the catalytic material obtained after the chemical treatment generally consists of metallic nanoparticles dispersed on an oxide,

thus leading to mechanisms for the reactivity distinct from the ones valid for ideal intermetallic surfaces.

\subsection{Pd-and Pt-based intermetallic catalysts}

One of the first intermetallic compound surfaces used as a catalyst is probably $\mathrm{Pt}_{3} \mathrm{Sn}(111)$. For the semi-hydrogenation of butadiene, the activities of its $\mathrm{p}(2 \times 2)$ or $(\sqrt{3} \times \sqrt{3})$ surfaces were found to be one order of magnitude lower than that of $\mathrm{Pt}(111)$ but the selectivity into butenes is largely increased by comparison to pure Pt (98-100\%) [83]. Theoretical studies on surface alloys showed that the presence of $\mathrm{Sn}$ at the surface weakens the chemisorption of unsaturated hydrocarbon molecules [84]. More complex intermetallics - as least when evaluated with the number of atoms in the cell - were also identified as potential catalysts for selective semi-hydrogenation reactions (Fig. 7), like $\mathrm{Pd}_{3} \mathrm{Ga}_{7}, \mathrm{Pd}_{2} \mathrm{Ga}$, PdGa [85-88]. Selectivity is expected to increase with the number of $\mathrm{Ga}$ atoms in the vicinity of the active $\mathrm{Pd}$ atoms, it has been demonstrated on $\mathrm{Pd}_{2} \mathrm{Ga}(010)$ [89]. Other compounds with similar compositions, like $\mathrm{Ga}_{2+x+y} \mathrm{Sn}_{4-x} \mathrm{Pd}_{9}$ do not present attractive performance [90], highlighting the challenge to predict the catalytic properties from the knowledge of the bulk structure. 


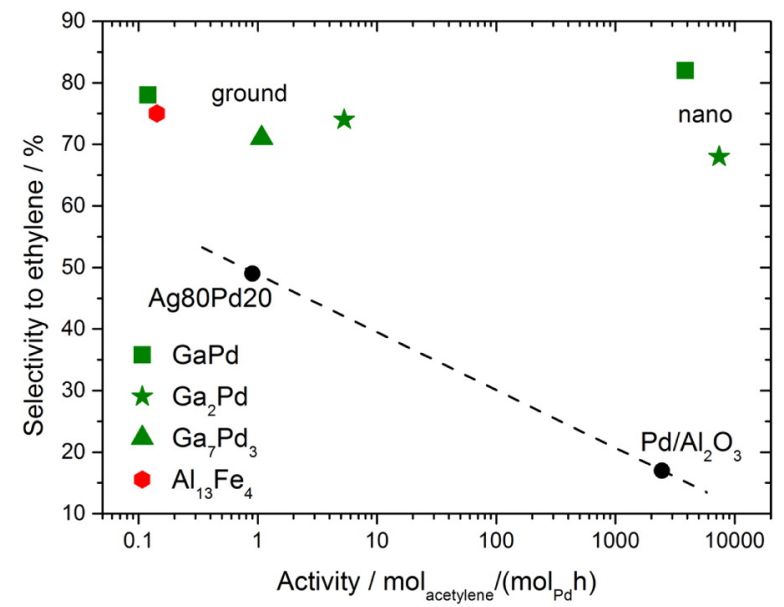

Fig. 7 Comparison of several intermetallic catalysts to supported 5\% $\mathrm{Pd} / \mathrm{Al}_{2} \mathrm{O}_{3}$ and the unsupported substitutional alloy $\mathrm{Ag}_{80} \mathrm{Pd}_{20}$. The dashed line is a guide to the eye. This figure is reproduced from ref. [73] (https://doi.org/10.1088/1468-6996/15/3/034803) under the licence Creative Commons Attribution 3.0 licence.

Surface structure is a decisive factor for catalytic performance [91-94]. In the cases of GaPd (and AlPd), corrugated surfaces with slightly protruding transitionmetal atoms forming a triangular arrangement with two neighboring $\mathrm{Al} / \mathrm{Ga}$ atoms are indeed highlighted as catalytically attractive surfaces, allowing the transition from the di- $\sigma$ bonded adsorption configuration for acetylene to a $\pi$-bonded adsorption of ethylene. The mechanism follows the one proposed by Horiuti and Polanyi in 1934 [95] and consists of three steps: (i) adsorption of the unsaturated molecule on the hydrogenated catalyst surface, (ii) hydrogen migration to the $\beta$-carbon of the unsaturated molecule and formation of a $\sigma$-bond between the catalyst surface and $\alpha$-C, and finally (iii) reductive elimination of the hydrogenated molecule. The large distances between the isolated active sites avoid undesired side-reactions such as oligomerization.

Hydrogenated surfaces are a clear requirement for this mechanism. On simple transition metal surfaces, atomic hydrogen is adsorbed on top sites. On GaPd or AlPd surfaces, $\mathrm{H}$ also generally adsorbs on transition metal top sites, with a few exceptions. For example, a Ga-H top interaction has been identified on $\mathrm{PdGa}(100)$ [96], highlighting that surface $\mathrm{Ga}$ atoms are not only a spacer, but part of the active site, as already postulated by M. Krajčí et al. [72,97]. 


\subsection{Non-noble intermetallic catalysts}

Highly active catalysts towards hydrogenation reactions are usually based on Ptgroup metals. There are not many solutions available today to replace these noble metals. Non-precious metal catalysts, especially those based on nickel (such as Raney nickel) have been developed as economical alternatives, but they are less active and/or selective than Pt-group metals and prone to deactivation $[98,99]$.

Al-based complex intermetallic compounds like $\gamma$ - $\mathrm{Al}_{4} \mathrm{Cu}_{9}$ or $\mathrm{Al}_{13} \mathrm{TM}_{4}(\mathrm{TM}=$ $\mathrm{Co}, \mathrm{Fe})$ have recently been identified as potential catalysts for hydrogenation reactions [87, 100-102]. For the semi-hydrogenation of acetylene, $\mathrm{Al}_{13} \mathrm{Fe}_{4}$ presents a high conversion and a high ethylene-selectivity of $81-84 \%$ (reaction conditions: $0.5 \% \mathrm{C}_{2} \mathrm{H}_{2}, 5 \% \mathrm{H}_{2}, 50 \% \mathrm{C}_{2} \mathrm{H}_{4}$ in $\mathrm{He}, 30 \mathrm{ml} \mathrm{min}^{-1}$ total flow, $200{ }^{\circ} \mathrm{C}$ ). For the hydrogenation of butadiene, the $\gamma-\mathrm{Al}_{4} \mathrm{Cu}_{9}(110)$ surface is active and $100 \%$ selective to butenes (2-20 mbar and temperatures of $\left.110-180^{\circ} \mathrm{C}\right)$.

As already mentioned, the presence of atomic hydrogen on the intermetallic surfaces is mandatory for the Horiuti and Polanyi mechanism. The dissociative adsorption of $\mathrm{H}_{2}$ on $\gamma-\mathrm{Al}_{4} \mathrm{Cu}_{9}(110)$ is the rate limiting step. It is likely caused by the high concentration of $\mathrm{Cu}$ in the topmost surface $(\mathrm{Cu}: \mathrm{Al}$ is $12: 6), \mathrm{H}_{2}$ dissociation occurring with a non negligible barrier on pure $\mathrm{Cu}(47 \mathrm{~kJ} / \mathrm{mol}$ [103]). Hydrogen dissociation is much easier when transition metals protrude at the surface, as in the case of the $\mathrm{Al}_{13} \mathrm{Co}_{4}(100)$ surface model obtained by bulk truncation $(17 \mathrm{~kJ} / \mathrm{mol})$ [104]. However, the combination of surface science studies and theoretical calculations point towards a dense Al-rich topmost layer for $\mathrm{Al}_{13} \mathrm{Co}_{4}(100)$ [105], leading to a rather high $\mathrm{H}_{2}$ dissociation barrier $(\simeq 52 \mathrm{~kJ} / \mathrm{mol})$ [106]. These observations highlight again the importance of surface structure on catalytic performances (Table 1).

Table 1 Dissociation, activation and desorption energies for the semi-hydrogenation of acetylene on complex Al-Co intermetallic surfaces. $E_{a}^{d i s}$ and $E_{a}^{i}$ are the activation energies for $\mathrm{H}_{2}$ dissociation and $\mathrm{C}_{2} \mathrm{H}_{x}$ hydrogenation, respectively. $E_{d}^{\mathrm{C}_{2} \mathrm{H}_{4}}$ is the ethylene desorption energy. Energies are given in $\mathrm{kJ} . \mathrm{mol}^{-1}$.

\begin{tabular}{llccccc}
\hline Surface & Model & $\mathrm{H}_{2} \rightarrow 2 \mathrm{H}^{2} \mathrm{C}_{2} \mathrm{H}_{x} \rightarrow \mathrm{C}_{2} \mathrm{H}_{x+1}$ & $\mathrm{C}_{2} \mathrm{H}_{4} \uparrow$ \\
& & $E_{a}^{d i s}$ & $E_{a}^{x=2}$ & $E_{a}^{x=3}$ & $E_{a}^{x=4}$ & $E_{d}^{\mathrm{C}_{2} \mathrm{H}_{4}}$ \\
\hline $\mathrm{Al}_{5} \mathrm{Co}_{2}(2 \overline{1} 0)$ & $\mathrm{P}_{B}[107]$ & 15 & 60 & 50 & 60 & 87 \\
$\mathrm{Al}_{5} \mathrm{Co}_{2}(2 \overline{1} 0)$ & $\mathrm{P}_{B-4 C o}[107]$ & - & 80 & 87 & 64 & 105 \\
$\mathrm{Al}_{13} \mathrm{Co}_{4}(100)$ & {$[104]$} & 17 & 63 & 61 & 80 & 70 \\
$\mathrm{Al}_{13} \mathrm{Co}_{4}(100)$ & {$[106]$} & 52 & 78 & 83 & 111 & 89 \\
\hline
\end{tabular}

In summary, intermetallic compound surfaces are promising for applications in catalysis. An enthalpic driving force usually prevents surface segregation, but $s p$ metals are subject to oxidation and therefore the surface of the intermetallic may deviate strongly from the bulk in the presence of oxygen. Their surfaces however provide isolation for the active site, which make them at least interesting model systems to further investigate single-atom catalysts [108]. 


\section{Conclusions}

We have presented a topical review of several areas of current interest relating to the structure and properties of surfaces of quasicrystals and other complex metallic alloys, and the formation of ultra-thin atomic and molecular films on these surfaces. Interest in these areas varies from fundamental curiosity about the behaviour of adsorbing materials on these surfaces to their potential for applications in economically important areas such as corrosion-resistance and catalysis. We hope to have demonstrated that the surfaces of complex metallic alloy surfaces, though not receiving perhaps the same levels of attention as simpler elemental and alloys surfaces, nonetheless merit an increasing level of scrutiny from the international surface science community.

Acknowledgements This work was partly supported by the Engineering and Physical Sciences Research Council, and the European Integrated Centre for the Development of New Metallic Alloys and Compounds. We dedicate this chapter to the memory of our colleague, mentor and friend An Pang Tsai who passed away in early 2019 after a short illness.

\section{References}

1. D. Shechtman, I. Blech, D. Gratias, J.W. Cahn, Phys. Rev. Lett. 53, 1951 (1984)

2. I. Hargittai, Journal of Molecular Structure 976(1-3), 81 (2010)

3. J.M. Dubois, Useful Quasicrystals (World Scientific, Singapore, 2005)

4. X.B. Zeng, G. Ungar, Y.S. Liu, V. Percec, S.E. Dulcey, J.K. Hobbs, Nature 428(6979), 157 (2004)

5. K. Hayashida, T. Dotera, A. Takano, Y. Matsushita, Physical Review Letters 98(19), 195502 (2007)

6. D.V. Talapin, E.V. Shevchenko, M.I. Bodnarchuk, X.C. Ye, J. Chen, C.B. Murray, Nature 461(7266), 964 (2009)

7. S. Fischer, A. Exner, K. Zielske, J. Perlich, S. Deloudi, W. Steurer, P. Lindner, S. Förster, Proceedings of the National Academy of Sciences 108(5), 1810 (2011)

8. C. Xiao, N. Fujita, K. Miyasaka, Y. Sakamoto, O. Terasaki, Nature 487, 349 (2012)

9. S. Förster, K. Meinel, R. Hammer, M. Trautmann, W. Widdra, Nature 502, 215 (2013)

10. K. Kamiya, T. Takeuchi, N. Kabeya, N. Wada, T. Ishimasa, A. Ochiai, K. Deguchi, K. Imura, N.K. Sato, Nature Communications 9(1), 154 (2018)

11. A.P. Tsai, A. Inoue, T. Masumoto, Journal of Materials Science Letters 6, 1403 (1987)

12. A.P. Tsai, Acc. Chem. Res. 36(1), 31 (2003)

13. A. Kortan, R. Becker, F. Thiel, H. Chen, Phys. Rev. Lett. 64, 200 (1990)

14. E.G. McRae, R.A. Malic, T.H. Lalonde, F.A. Thiel, H.S. Chen, A.R. Kortan, Phys. Rev. Lett. 65, 883 (1990)

15. P.A. Thiel, R. McGrath, Surfaces of Quasicrystals and Complex Metallic Alloys (Wiley, Berlin). Handbook of Surface and Interface Science.

16. A.I. Goldman, R.F. Kelton, Reviews of Modern Physics 65(1), 213 (1993)

17. Z. He, H. Li, H. Ma, G. Li, Scientific Reports 7, 40510 (2017)

18. D. Naumović, Progress in Surface Science 75(3-8), 205 (2004)

19. J.A. Smerdon, J.K. Parle, R. McGrath, B. Bauer, P. Gille, Zeit. Kristallographie 224, 13 (2009) 
20. S.S. Hars, H.R. Sharma, J.A. Smerdon, T.P. Yadav, A. Al-Mahboob, J. Ledieu, V. Fournée, R. Tamura, R. McGrath, Physical Review B 93(20), 205428 (2016)

21. K. Urban, M. Feuerbacher, J. Non-Crystalline Solids 334-335, 143 (2004)

22. J.M. Dubois, An introduction to complex metallic alloys and to the CMA Network of Excellence (World Scientific, Singapore, 2007), Complex Metallic Alloys, vol. 1, book section 1, pp. 1-29

23. J.A. Smerdon, H.R. Sharma, J. Ledieu, R. McGrath, J. Phys.: Condens. Matter 20, 314005 (2008)

24. J.A. Smerdon, L.H. Wearing, J.K. Parle, L. Leung, H.R. Sharma, J. Ledieu, R. McGrath, Philos. Mag. 88, 2073 (2008)

25. R. McGrath, J.A. Smerdon, H.R. Sharma, W. Theis, J. Ledieu, J. Phys.-Condensed Matter 22(8), $084022(2010)$

26. H.R. Sharma, K. Nozawa, J.A. Smerdon, P.J. Nugent, I. McLeod, V.R. Dhanak, M. Shimoda, Y. Ishii, A.P. Tsai, R. McGrath, Nature Communications 4, 2715 (2013)

27. H.R. Sharma, M. Shimoda, K. Sagisaka, H. Takakura, J.A. Smerdon, P.J. Nugent, R. McGrath, D. Fujita, S. Ohhashi, A.P. Tsai, Phys. Rev. B 80(12), 121401 (2009)

28. C. Cui, P.J. Nugent, M. Shimoda, J. Ledieu, V. Fournée, A.P. Tsai, R. McGrath, H.R. Sharma, Journal of Physics: Condensed Matter 26(1), 015001 (2014)

29. C. Cui, P.J. Nugent, M. Shimoda, J. Ledieu, V. Fournée, A.P. Tsai, R. McGrath, H.R. Sharma, Journal of Physics: Condensed Matter 24(44), 445011 (2012)

30. S. Hars, H. Sharma, J. Smerdon, S. Coates, K. Nozawa, A. Tsai, R. McGrath, Surface Science 678, 222 (2018)

31. H. Takakura, C.P. Gómez, A. Yamamoto, M. de Boissieu, A. Tsai, Nature Materials 6, 58 (2007)

32. K. Nozawa, Y. Ishii, Journal of Physics: Conference Series 809(1), 012018 (2017)

33. K.J. Franke, H.R. Sharma, W. Theis, P. Gille, P. Ebert, K.H. Rieder, Phys. Rev. Lett. 89(15), 156104 (2002)

34. H.R. Sharma, M. Shimoda, A.R. Ross, T.A. Lograsso, A.P. Tsai, Phys. Rev. B 72(4), 045428 (2005)

35. J. Ledieu, L. Leung, L.H. Wearing, R. McGrath, T.A. Lograsso, D. Wu, V. Fournée, Phys. Rev. B. 77, 073409 (2008)

36. J.A. Smerdon, J.K. Parle, L.H. Wearing, T.A. Lograsso, A.R. Ross, R. McGrath, Phys. Rev. B 78, 075407 (2008)

37. V. Fournée, H.R. Sharma, M. Shimoda, A.P. Tsai, B. Ünal, A.R. Ross, T.A. Lograsso, P.A. Thiel, Phys. Rev. Lett. 95(15), 155504 (2005)

38. H.R. Sharma, V. Fournée, M. Shimoda, A.R. Ross, T.A. Lograsso, P. Gille, A.P. Tsai, Phys. Rev. B 78(15), 155416 (2008)

39. J.A. Smerdon, N. Cross, V.R. Dhanak, H.R. Sharma, K.M. Young, T.A. Lograsso, A.R. Ross, R. McGrath, J. Phys.: Condens. Matter 22(34), 345002 (2010)

40. J. Ledieu, J.T. Hoeft, D.E. Reid, J.A. Smerdon, R.D. Diehl, T.A. Lograsso, A.R. Ross, R. McGrath, Phys. Rev. Lett. 92, 135507 (2004)

41. J.A. Smerdon, J. Ledieu, J.T. Hoeft, D.E. Reid, L.H. Wearing, R.D. Diehl, T.A. Lograsso, A.R. Ross, R. McGrath, Philos. Mag. 86, 841 (2006)

42. K. Pussi, M. Gierer, R.D. Diehl, J. Phys.: Condens. Matter 21, 474213 (2009)

43. J. Ledieu, C.A. Muryn, G. Thornton, R.D. Diehl, T.A. Lograsso, D.W. Delaney, R. McGrath, Surf. Sci. 472(1-2), 89 (2001)

44. E.J. Cox, J. Ledieu, V.R. Dhanak, S.D. Barrett, C.J. Jenks, I. Fisher, R. McGrath, Surf. Sci. 566-568, 1200 (2004)

45. J.A. Smerdon, K.M. Young, M. Lowe, S.S. Hars, T.P. Yadav, D. Hesp, V.R. Dhanak, A.P. Tsai, H.R. Sharma, R. McGrath, Nano Letters 14(3), 1184 (2014)

46. V. Fournée, E. Gaudry, J. Ledieu, M.C. de Weerd, D. Wu, T. Lograsso, ACS Nano 8(4), 3646 (2014)

47. T. Cai, J. Ledieu, R. McGrath, V. Fournée, T.A. Lograsso, A.R. Ross, P.A. Thiel, Surf. Sci. 526(1-2), $115(2003)$ 
48. D. S., F. F., S. W, Acta Crystallographica Section B 67(1), 1 (2011)

49. Z. Papadopolos, G. Kasner, J. Ledieu, E.J. Cox, N.V. Richardson, Q. Chen, R.D. Diehl, T.A. Lograsso, A.R. Ross, R. McGrath, Phys. Rev. B 66, 184207 (2002)

50. B. Ünal, C.J. Jenks, P.A. Thiel, J. Phys. Condens. Matter 21(5), 055009 (2009)

51. M. Krajčí, J. Hafner, J. Ledieu, V. Fournée, Journal of Physics: Conference Series 226, 012005 (2010)

52. N. Kalashnyk, J. Ledieu, E. Gaudry, C. Cui, A. Tsai, V. Fournée, Nano Research 11(4), 2129 (2018)

53. M. Shimoda, T.J. Sato, A.P. Tsai, J.Q. Guo, Phys. Rev. B 62(17), 11288 (2000)

54. M. Shimoda, J.Q. Guo, T.J. Sato, A.P. Tsai, Jpn. J. Appl. Phys. 40(10), 6073 (2001)

55. M. Shimoda, J.Q. Guo, T.J. Sato, A.P. Tsai, Surf. Sci. 482-485, 784 (2001)

56. J. Ledieu, J.T. Hoeft, D.E. Reid, J.A. Smerdon, R.D. Diehl, N. Ferralis, T.A. Lograsso, A.R. Ross, R. McGrath, Phys. Rev. B 72(3), 035420 (2005)

57. M. Bielmann, A. Barranco, P. Ruffieux, O. Gröning, R. Fasel, R. Widmer, P. Gröning, Adv. Eng. Mat. 7, 392 (2005)

58. J.M. Dubois, Chem. Soc. Rev. 41, 6760 (2012)

59. U. Bardi, Rep. Prog. Phys. 57, 939 (1994)

60. M. Shimoda, T.J. Sato, A.P. Tsai, J.Q. Guo, Surf. Sci. 507, 276 (2002)

61. D. Reid, J.A. Smerdon, J. Ledieu, R. McGrath, Surf. Sci. 600(18), 4132 (2006)

62. T. Duguet, J. Ledieu, J.M. Dubois, V. Fournee, Journal of Physics-Condensed Matter 20(31), 314009 (2008)

63. T. Duguet, E. Gaudry, T. Deniozou, J. Ledieu, M.C. de Weerd, T. Belmonte, J.M. Dubois, V. Fournée, Physical Review B 80(20) (2009)

64. E. Gaudry, A.K. Shukla, T. Duguet, J. Ledieu, M.C. deWeerd, J.M. Dubois, V. Fournée, Physical Review B 82(8) (2010)

65. R. Addou, A.K. Shukla, S.A. Villaseca, E. Gaudry, T. Deniozou, M. Heggen, M. Feuerbacher, R. Widmer, O. Gröning, V. Fournée, J.M. Dubois, J. Ledieu, New Journal of Physics 13, $103011(2011)$

66. R. Mola, T. Bucki, K. Wcislo, Archives of Foundry Engineering 14, 85 (2014)

67. J. Kadok, K. Pussi, S. Šturm, B. Ambrožič, E. Gaudry, M.C. de Weerd, V. Fournée, J. Ledieu, Physical Review Materials 2(4), 043405 (2018)

68. R. Darolia, U.S. Patent 6,630,250, B1, Oct. 7 (2003)

69. N. Gall', E. Rut'kov, A. Tontegode, Physics of the Solid State 48, 369 (2006)

70. J.D.R. Buchanan, T.P.A. Hase, B.K. Tanner, P.J. Chen, L. Gan, C.J. Powell, W.F. Egelhoff, Phys. Rev. B 66, 104427 (2002)

71. S. Furukawa, T. Komatsu, ACS Catal. 7, 735 (2017)

72. M. Krajčí, J. Hafner, ChemCatChem 8, 34 (2016)

73. M. Armbrüster, R. Schlögl, Y. Grin, Science and Technology of Advanced Materials 15, 034803 (2014)

74. J. Hafner, M. Krajčí, Accounts of Chemical Research 47, 3378 (2014)

75. A. Tsai, S. Kameoka, K. Nozawa, M. Shimoda, Y. Ishii, Accounts of Chemical Research 50, $2879(2017)$

76. A.P. Tsai, S. Kameoka, Y. Ishii, J. Phys. Soc. Jpn. 73, 3270 (2004)

77. B.P. Ngoc, C. Geantet, M. Aouine, G. Bergeret, S. Raffy, S. Marlin, International Journal of hydrogen energy 33, 1000 (2008)

78. T. Tanabe, S. Kameoka, A.P. Tsai, Catalysis Today 111, 153 (2006)

79. S. Kameoka, T. Tanabe, A. Tsai, Catalysis Today 93-5, 23 (2004)

80. M. Yoshimura, A. Tsai, Journal of Alloy and Compounds 342, 451 (2002)

81. H. Takakura, J. Guo, A. Tsai, Philosophical Magazine Letters 81, 411 (2001)

82. S. Kameoka, S. Wakabayashi, E. Abe, A.P. Tsai, Catal Lett 146, 1309 (2016)

83. Y. Jugnet, R. Sedrati, J. Bertolini, Journal of Catalysis 229, 252 (2005)

84. C. Becker, J. Haubrich, K. Wandelt, F. Delbecq, D. Loffreda, P. Sautet, J. Phys. Chem. C 112, 14693 (2008)

85. M. Armbrüster, K. Kovnir, M. Behrens, D. Teschner, Y. Grin, R. Schlögl, J. Am. Chem. Soc. 132, 14745 (2010) 
86. K. Kovnir, J. Osswald, M. Armbrüster, D. Teschner, G. Weinberg, U. Wild, A. Knop-Gericke, T. Ressler, Y. Grin, R. Schlögl, Journal of Catalysis 264, 93 (2009)

87. J. Osswald, R. Giedigkeit, R.E. Jentoft, M. Armbrüster, F. Girgsdies, K. Kovnir, T. Ressler, Y. Grin, R. Schlögl, Journal of Catalysis 258, 210 (2008)

88. J. Osswald, K. Kovnir, M. Armbrüster, R. Giedigkeit, R.E. Jentoft, U. Wild, Y. Grin, R. Schlögl, Journal of Catalysis 258, 219 (2008)

89. M. KrajciKrajčí, J. Hafner, J. Phys. Chem C 118, 12285 (2014)

90. O. Matselko, U. Burkhardt, Y. Prots, R. Zimmermann, M. Armbruester, R. Gladyshevskii, Y. Grin, European Journal of Inorganic Chemistry 29, 3542 (2017)

91. M. Krajčí, J. Hafner, The Journal of Physical Chemistry C 116, 6307 (2012)

92. M. Krajčí, J. Hafner, Journal of Catalysis 295, 70 (2012)

93. M. Krajčí, J. Hafner, Phys. Rev. B 87, 035436 (2013)

94. M. Krajčí, J. Hafner, Journal of Catalysis 312, 232 (2014)

95. M. Polanyi, J. Horiuti, J. Trans. Faraday Soc. 30, 1164 (1934)

96. P. Bechthold, J. Ardenghi, O. Nagel, A. Juan, E. González, P. Jasen, International Journal of Hydrogen Energy 39, 2093 (2014)

97. M. Sandoval, P. Bechthold, V. Orazi, E. González, A. Juan, P. Jasen, Applied Surface Science 435, 568 (2018)

98. A.B. Mekler, S. Ramachandran, S. Swaminathan, M.S. Newman, Org. Synth. 5, 743 (1973)

99. C.F.H. Allen, J. VanAllan, Org. Synth. 3, 827 (1955)

100. L. Piccolo, L. Kibis, M.C.D. Weerd, E. Gaudry, J. Ledieu, V. Fournée, ChemCatChem (2017)

101. M. Armbrüster, K. Kovnir, M. Friedrich, D. Teschner, G. Wowsnick, M. Hahne, P. Gille, L. Szentmiklosi, M. Feuerbacher, M. Heggen, F. Girgsdies, D. Rosenthal, R. Schlögl, Y. Grin, Nat. Mater. 11, 690 (2012)

102. M. Armbrüster, K. Kovnir, Y. Grin, R. Schlögl, P. Gille, M. Heggen, M. Feuerbacher, European Patent 09157875.7 (2009)

103. C. Diaz, E. Pijper, R.A. Olsen, H.F. Busnengo, D.J. Auerbach, G.J. Kroes, Science 326, 832 (2009)

104. M. Krajčí, J. Hafner, J. Catal. 278, 200 (2011)

105. E. Gaudry, C. Chatelier, G. McGuirk, L.S. Loli, M.C.D. Weerd, J. Ledieu, V. Fournée, R. Felici, J. Drnec, G. Beutier, M. de Boissieu, Phys. Rev. B 94, 165406 (2016)

106. D. Kandaskalov, V. Fournée, J. Ledieu, E. Gaudry, The Journal of Physical Chemistry C 121(34), 18738 (2017)

107. M. Meier, J. Ledieu, V. Fournée, E. Gaudry, J. Phys. Chem. C 121, 4958 (2017)

108. T. Yamada, T. Kojima, E. Abe, S. Kameoka, Y. Murakami, P. Gille, A.P. Tsai, Journal of the American Chemical Society 140, 3838 (2018) 